\title{
PROPENSITY FOR FALLS IN ELDERLY FEMALE AND MALE PRACTITIONERS AND NON- PRACTITIONERS OF PHYSICAL ACTIVITIES
}

\author{
Élcio Alves Guimarães' ${ }^{1}$ Cristina de Matos Boaventura², Maria Paula Pereira Andrade², Nayara Ribeiro Graciano², \\ Bárbara Vilela Franco Teodoro², Kennedy Rodrigues Lima ${ }^{1,3}$
}

\begin{abstract}
Background: Aging being a natural physiological process can present both physical and psychic changes, due to the conditions of life of the person, and can be influencers for the installation of chronic non-communicable diseases, which may predispose this subject to an episode of fall. Objectives: To compare the propensity to fall in the elderly male and female, practitioners and non-practitioners of physical activities. Methods: The sample consisted of 120 elderly people of both genders practitioners and non-practitioners of physical activity and were used the "Timed Up and Go" and "Functional Reach" tests. Results: Among non-practitioners of physical activity, significant differences were observed between the values of functionality, being that the male group presented higher values than the female group, i.e., men move more, therefore has the lowest risk of fall. Conclusion: It was concluded that the female practitioners of physical activity have a greater risk of suffering an episode of fall compared to the non-practitioners, and in relation to the men practitioners and non-practitioners of physical activity there was no significant difference, showing that the elderly women have a higher risk to fall compared to the elderly men.
\end{abstract}

Keywords: Elderly; Physical Activity; Falls, Timed Up and Go, Functional Reach.

\section{INTRODUCTION}

As shown in epidemiological studies, the number of elderly citizens has been increasing for about four decades mainly in developing countries. This growth presents constant challenges in the area of health and socioeconomic aspects, arising from the own population aging ${ }^{(1)}$. According to Meireles et al., the profile of the elderly subject differs between developed countries and developing countries as definition established by the United Nations in 1982, through Resolution 39/125, during the first United Nations World Assembly on the population aging. In developing countries people are considered elderly as soon as they reach the age group of 65 years or more, whereas in developing countries, as Brazil, they are considered elderly from the age group of 60 years or more ${ }^{(2)}$. Brazil will have 30 millions of its population constituted by the elderly by the year 2020, according to estimates, being added to this classification 650 thousand subjects per year, predominantly female. The female predominance of $55.1 \%$ of the elderly in Brazil in 2000 and $55.8 \%$ in 2010, can be explained by the fact that women have a life expectancy of 8 years higher than men ${ }^{(3)}$. Therefore, aging as a natural process, may be arising along of both physical and psychological changes due to the conditions of life of the person, and these may be influencers for the installation of chronic non-communicable diseases, which may predispose this subject to falls. It is observed that an unintentional change of position due to the agglomeration of alterations around the body balance of the elderly, leads to a decrease in their compensatory capacity, consequently increasing instability and the risk of falling ${ }^{(4)}$.

According to a study of Maciel (2010), the participation of the elderly in physical activity programs is an independent way to reduce and prevent a series of functional declines associated to aging. There are several benefits in an active elderly life and they can be classified biologically, psychologically and socially, as the increase or maintenance of aerobic capacity and muscle mass; decline in mortality rate; prevention of coronary diseases; alteration of body composition by reduction of fat tissue level and reduction of risk of sarcopenia; decrease of dementia, anxiety and stress; and improvement in self-esteem, self-confidence, humor and quality of life ${ }^{(5)}$.

Corresponding Author: Élcio Alves Guimarães. Address: Av. Dos Vinhedos, 900, Morada da Colina, Uberlândia, MG, Brazil. Cep: $38411-159$.

Telephone: (+55) 34 996874951. Email: elcio@triang.com.br

${ }^{1}$ Universidade Federal de Uberlândia (UFU), Uberlândia (MG), Brasil.

Full list of author information is available at the end of the article.

Financial support: The authors declare that there was no financial support.

Submission date 10 August 2018; Acceptance date 30 September 2018; Publication date 08 January 2019 
It is observed in the literature different instruments that allow us to individually identify the risk of falls in the elderly, and through these findings determine actions to assist this population effectively and safely. Among these instruments, there is the Time Up And Go test (TUG) ${ }^{(6)}$, which is one of the most used clinical tools to evaluate the gait and balance of elderly individuals ${ }^{(7)}$. Also having the same purpose, there is the Functional Reach Test (FRT), an instrument that identifies the dynamic changes of postural control(6), and it is used to evaluate the previous functional range of the subject, measuring the limits of stability when he/she is in an ophthostatic position ${ }^{(8)}$. In view of the above, the study is justified in order to improve knowledge about the risk of falls in the elderly, since it is known that the prevalence is high, using physical activity as a way to prevent falls in this population, since it contributes to the reduction of the risk of falls in the elderly ${ }^{(5)}$. Therefore, the objective of the present study was to compare the propensity to fall in the elderly female and male practitioners and non-practitioners of physical activities.

\section{METHODS}

This is a descriptive, quantitative, cross-sectional study. The non-probability, convenience sample was composed by 120 elderlies from the Support Center in Uberlândia (MG), Brazil, with 30 male practitioners of regular physical activity and 30 non-practitioners, and 30 female practitioners of regular physical activity and 30 non-practitioners. It was included in the study elderly people between 60 and 100 years of age, without visual deficits, who were in good health and walking, and who signed the Informed Consent Form. The exclusion criteria were: subjects visually impaired (blind) and those with signs and symptoms that put their health at risk during the test, as uncontrolled hypertension, vertigo, unstable angina, recent pulmonary embolism, uncontrolled arrhythmias, decompensated congestive heart failure (CHF), hypotension (80/50 mmHg), tachycardia above 120 bpm, lower limb fractures in the last 3 months, presence of orthoses and pain that impairs ambulation. The elderlies were approached and invited to participate in the research that was carried out from March to April 2016. During the approach were presented the objectives of the research, the clarifications about the criterion of secrecy and the freedom to not participate, without any prejudice due to the bond established with the Center, as well as the condition of signing the Informed Consent Form. In case of acceptance, it was requested the signature of the Form before the data collection. The study was approved by the Ethics Committee of the Centro Universitário do Triângulo - UNITRI no 1.366.273.

The "Timed Up and Go Test" (TUG) and "Functional Reach Test" (FRT) tests were used to assess the propensity for falls. TUG is a balance test commonly used to examine functional mobility. The test requires the individual to lift the chair, walk for 3 meters, come back, return and sit back in the chair.
Being instructed to perform the task quickly and as safely as possible, its performance being analyzed through the time it takes to complete the task completely. This individual can be classified as follows according to the time spent: $<10$ seconds, independent and without change of balance; $<20$ seconds, dependent on basic transfers; > 20 seconds, dependent on many activities of daily living and mobility, indicating the need for appropriate intervention in the case ${ }^{(6)}$.

For the application of the TUG test, a chair without arms was used, a Vollo VL-512 (Vollo Sports, São Paulo, Brazil) digital chronometer with memory to measure up to ten laps and counters for data annotation. Prior to the start of the examination the volunteers received information about the execution of the test and, from the examiner's command voice, the test was started. At the beginning of the timing the volunteer started from the initial position with his back resting on the back of the chair, upper limbs along his body and feet parallel to the floor, raised from the armless chair, walked the distance of 3 meters and returned to the chair in the shortest time possible. Volunteers were allowed to take the test twice, the first being for apprenticeship only (the volunteer was not allowed to receive any help from another person during the test).

FRT is a test used for the evaluation and identification of dynamic changes in postural control, developed in 1990 by Duncan et al. In this test, the patient is positioned with the right shoulder standing next to a wall, where a ruler or tape measure is placed to measure the length of the upper limb, asking the patient to flex the arm 90 o by positioning the fingers of the hand in extension. When the length of the limb is measured, the patient still in the same position is required to perform an anterior trunk displacement by extending the arm forward, in an attempt to pick up some object, without taking steps forward or using any compensation strategy. balance. After the test, the result comes from the average of three attempts, by means of the difference of the measurement in the initial position and the final marked in the ruler positioned in the wall. Thus, displacements with measures of less than $15 \mathrm{~cm}$ are indicative of patient fragility and risk of falls ${ }^{(6)}$.

\section{RESULTS}

During the data collection, 70 females and 75 males were invited to participate in the study, but 10 females and 15 males refused to participate for personal reasons. Therefore, 120 subjects participated, of which 60 (50\%) were males, 30 practitioners of physical activities and 30 non-practitioners; and 60 (50\%) of the female gender, 30 practitioners of physical activities and 30 non-practitioners. Among the participants, the most reported activities were walking, water aerobics and dancing, which were performed at least three times a week, with duration of one hour. Table 1 shows the values related to age, the TUG and FRT tests, considering the four subgroups. 
Table 1. Values related to age and TUG and FRT tests.

\begin{tabular}{|c|c|c|c|c|}
\hline Variables & Minimum Values & Maximum Values & Mean & Standard Deviation \\
\hline \multicolumn{5}{|l|}{ Male } \\
\hline \multicolumn{5}{|l|}{ Practitioners } \\
\hline Age & 60 years & 87 years & 68 years to $10 \mathrm{~m}$ & 5 years to $11 \mathrm{~m}$ \\
\hline TUG (seconds) & 4.38 & 10.76 & 6.82 & 1.55 \\
\hline FRT(centimeters) & 7.66 & 51 & 31.37 & 10.41 \\
\hline \multicolumn{5}{|l|}{ Non-practitioners } \\
\hline Age & 61 years & 98 years & 71 years to $6 \mathrm{~m}$ & 7 years to $7 m$ \\
\hline TUG (seconds) & 4.00 & 16.56 & 7.50 & 2.58 \\
\hline FRT(centimeters) & 11.00 & 43.00 & 27.74 & 8.98 \\
\hline \multicolumn{5}{|l|}{ Female } \\
\hline \multicolumn{5}{|l|}{ Practitioners } \\
\hline Age & 61 years & 82 years & 70 years to $2 \mathrm{~m}$ & 5 years to $10 \mathrm{~m}$ \\
\hline TUG (seconds) & 5.84 & 14.14 & 8.14 & 2.02 \\
\hline FRT(centimeters) & 7 & 33 & 12.65 & 4.95 \\
\hline \multicolumn{5}{|l|}{ Non-practitioners } \\
\hline Age & 61 years & 82 years & 69 years to $4 \mathrm{~m}$ & 6 years to $2 m$ \\
\hline TUG (seconds) & 5.13 & 11.34 & 7.81 & 1.75 \\
\hline FRT(centimeters) & 9.30 & 39.00 & 22.82 & 8.11 \\
\hline
\end{tabular}

Note: $T U G=$ Time Up And Go test; FRT= Functional Reach Test.

As observed in table 1 , in the TUG test, the male practitioners had mean of $6.82^{\prime \prime}+/-1.55^{\prime \prime}$, while the male non-practitioners had a mean of $7.50^{\prime \prime}+/-2.58^{\prime \prime}$. The female practitioners had a mean of $8.14^{\prime \prime} \mathrm{cm}+/-2.02 \mathrm{~cm}$, while the non-practitioners had a mean of $7.81 "+/-1.75$. Therefore, it was observed that no volunteer took more than 10 seconds to complete the test, thus being considered all independent in their basic daily activities. Regarding the FRT, the mean for the male practitioners was $31.37 \mathrm{~cm}+/-10.41 \mathrm{~cm}$ and for the male non-practitioners the mean was $27.74 \mathrm{~cm}+/-8.98 \mathrm{~cm}$, indicating that the men of both groups did not present risk of falling because they had displacements greater than $15 \mathrm{~cm}$. Whereas the female practitioners had mean of $12.65 \mathrm{~cm}+/-4.95 \mathrm{~cm}$ and the non-practitioners had mean of $22.82 \mathrm{~cm}+/-8.11 \mathrm{~cm}$, indicating that women who practice physical activities have an increased propensity of falling since they have moved less than $15 \mathrm{~cm}$. In order to verify the existence of correlations between the values of age, TUG and FRT, was applied the Spearman Correlation Coefficient ${ }^{(9)}$. The significance level was 0.05. The results are shown in table 2 .

As observed in table 2, there is a negative correlation between TUG and FRT variables in the male non-practitioners, i.e., the longer the subject took in the TUG, the shorter the displacement in the FRT. Regarding the female practitioners, it was observed a significant positive correlation between the Age and TUG variables, i.e., the greater the age of the volunteer, the longer her TUG time. Another data found in female practitioners and non-practitioners was a significant
Table 2. Values of rs and the probabilities associated to it, obtained through the Spearman Correlation Coefficient for age, TUG and FRT.

\begin{tabular}{cccccc}
\hline \multirow{2}{*}{$\begin{array}{c}\text { Analyzed } \\
\text { Variables }\end{array}$} & \multicolumn{2}{c}{ Male } & & \multicolumn{2}{c}{ Female } \\
\cline { 2 - 3 } \cline { 5 - 6 } & $\begin{array}{c}\text { Values } \\
\text { of rs }\end{array}$ & Probabilities & $\begin{array}{c}\text { Values } \\
\text { of rs }\end{array}$ & Probabilities \\
\hline Practitioners & & & & \\
Age x TUG & 0.2314 & 0.219 & & 0.4557 & $0.011^{*}$ \\
Age x FRT & 0.1218 & 0.522 & & -0.2407 & 0.200 \\
Tug x FRT & -0.1362 & 0.473 & & -0.4805 & $0.007^{*}$ \\
Non-practitioners & & & & & \\
Age x TUG & 0.2329 & 0.215 & & 0.2724 & 0.145 \\
Age x FRT & -0.2298 & 0.222 & & 0.0846 & 0.657 \\
Tug x FRT & -0.4923 & $0.006^{*}$ & -0.3829 & $0.037^{*}$ \\
\hline
\end{tabular}

Note: TUG = Time Up And Go test; FRT = Functional Reach Test; $\left({ }^{*}\right) \mathrm{p}<0.05$

negative correlation between the TUG and FRT variables, indicating that the longer the time to perform the TUG test, the shorter the displacement in the FRT. With the interest of verifying the existence of significant differences between the values of age, TUG and FRT, obtained by the male and female of both groups, was applied the Mann-Whitney $U$ test $^{(9)}$. The significance level was 0.05 . The results are shown in table 3.

As observed in Table 3, no significant differences were observed between the values of the variables analyzed in the male groups. Regarding the female, significant differences 
were found between practitioners and non-practitioners in the FRT, i.e., women who practice physical activity move less, presenting a risk of falls. In order to verify the existence of significant difference between the results obtained by the male and the female, was applied the Mann-Whitney ${ }^{(9)}$ test for values related to age, the TUG and FRT tests, considering the four subgroups. The significance level was 0.05 . The results are shown in table 4.

According to the results shown in table 4, significant differences were found between the TUG and FRT values of male and female practitioners of physical activities, being that, in relation to the TUG, the female group obtained higher values than the male group, i.e., women spent more time to perform the test when compared to men. Regarding the FRT, the female practitioners obtained lower values than the male, i.e., they moved less than the men, thus having a higher risk of falls. In the non-practitioners, significant differences were observed between the FRT values, and the male obtained higher values than the female, i.e., men moved more, therefore they had the lowest risk of fall.

\section{DISCUSSION}

There is an increase in the number of elderly subjects in Brazil, which is already noticeable in developed nations. And with age, naturally occur changes in the body, and it can be observed the reduction of muscle mass, which consequently reduces muscle strength and decrease in bone density, leading to weakening skeletal structure. These changes trigger reflexes in posture, gait development, and balance, which potentiate the occurrence of a fall event ${ }^{(10)}$. Falls are present in the lives

Table 3. Probabilities of age, TUG and FRT when applied the Mann-Whitney test.

\begin{tabular}{ccccc}
\hline \multirow{2}{*}{ Analyzed Variables } & Male & & Female \\
\cline { 2 - 3 } & Probabilities & & Probabilities \\
\hline Age - practitioners x non-practitioners & 0.1706 & & 0.5887 \\
TUG - practitioners x non-practitioners & 0.3994 & & 0.6414 \\
FRT - practitioners x non-practitioners & 0.1352 & & $0.0000^{*}$ \\
\hline
\end{tabular}

Note: TUG= Time Up And Go test; FRT= Functional Reach Test. $\left({ }^{*}\right) p<0.05$

Table 4. Probabilities obtained through the Mann-Whitney test for age, TUG and FRT, considering the four subgroups.

\begin{tabular}{lc}
\hline \multicolumn{1}{c}{ Analyzed Variables } & Probabilities \\
\hline Age - male x female practitioners & 0.2859 \\
TUG - male x female practitioners & $0.0080^{*}$ \\
FRT - male x female practitioners & $0.0000^{*}$ \\
Age - male x female non-practitioners & 0.2328 \\
TUG - male x female non-practitioners & 0.2612 \\
FRT - male x female non-practitioners & $0.0345^{*}$ \\
\hline
\end{tabular}

Note: TUG= Time Up And Go test; FRT= Functional Reach Test. $\left({ }^{*}\right) p<0.05$ of a large part of the elderly and this is not only a factor of demotivation and insecurity, but also represents one of the causes of morbidity and mortality for these subjects. Being fundamental for the elderly the safety and independence to perform their activities in a calm and healthy way and the physical activity provides a better quality of life, allowing them to carry out their activities of daily living. Physical activity is important because sedentary people develop several problems due to the disuse of the physiological functions and not only due to age. Therefore, it is fundamental to maintain the functions of the body so that life expectancy is greater ${ }^{(11)}$.

In the present research, during the TUG, in which the intention is to verify in the participants the capacity of independence in their basic daily activities, was observed that all groups obtained results less than 10 seconds to perform the test, i.e., all participants are independent in their activities of daily living ( $A D L$ ). No studies were found in the literature evaluating TUG in male and female practitioners and non-practitioners of physical activities. However, in the study of Bretan, Silva Júnior and Ribeiro (2013), in which 102 subjects were evaluated (66\% female and $34 \%$ male, mean age of $78+/-7$ years), it was verified that a total of $70 \%$ of the participants were also considered independent because they performed the test in less than 10 seconds $^{(12)}$. In the FRT test, in which the fragility in the risk of fall is evaluated, the male practitioners and non-practitioners of physical activity moved more than $15 \mathrm{~cm}$ and were considered without risk of falls, while in the female groups only the practitioners had mean lower than $15 \mathrm{~cm}$, which demonstrated a higher risk of falls in this group. According to a study in which 30 elderly women were evaluated on the previous functional scope test, they obtained $100 \%$ of their sample> $15 \mathrm{~cm}$, which corroborates the finding of the present study when compared to the group of non-pregnant women However, in the study in question, the sample of 30 women were in different levels of physical fitness ${ }^{(13)}$.

When a portion of the elderly female population practicing and not practicing physical activities (144 females with age between 65 and 96 years) was evaluated by Ribeiro et al. (2009), it was observed that the practitioners obtained $25 \%$ better performance of the FRT than non-practitioners, thus observing the great benefit of physical activity for this group ${ }^{(14)}$. These data were divergent from the present study, since the non-practitioners obtained better results in FRT. In another research the sample was composed by 147 elderlies, and 94 females with mean age of 71.38 years had a FRT mean of $12.93 \mathrm{~cm}$, indicating higher risk of falls ${ }^{(15)}$. These results agree with those found in present study, with $12.65 \mathrm{~cm}$ for the female practitioners.

The objective of the present research was to compare the propensity to fall in the elderly female and male practitioners and non-practitioners of physical activities. It is noted through the research that the risk of falling in the elderly may be 
correlated with age, since in the female practitioners of physical activity, the age and TUG had a positive correlation. Souza et al. (2013), found similar results to this study, when they evaluated 341 elderly people of both genders, and found a significant difference between the TUG mean when compared the age range, in which the elderlies from 60 to 69 years had a mean significantly lower than the mean of elderlies with 80 years or more (11.6" and 12.6 ", respectively), showing that the greater the age, the longer the time to perform TUG and the less independence for $\mathrm{ADL}^{(16)}$. In the study of Almeida et al. (2012), with a sample of 267 elderlies (both genders and 60 years or more), it was observed that the advancement of age has been associated with increasing in TUG values, i.e., the older, the more time spent to perform the test ${ }^{(17)}$. In the present study, when correlating FRT with TUG, it was found a negative correlation in the female and male non-practitioners of physical activity and in the female practitioners, indicating that the longer the execution time of TUG, the lower the displacement in FRT. Similar data were also demonstrated by Neto \& Guimarães (2012), who assessed 30 people of both genders with age over 65 years, had 15 practitioners of physical activity with mean of $10^{\prime \prime}$ in TUG and $29 \mathrm{~cm}$ in FRT and 15 non-practitioners with 14" in TUG and $16 \mathrm{~cm}$ in $\mathrm{FRT}^{(11)}$, demonstrating that the longer the execution time of TUG, the lower the displacement in FRT. It is verified in the present study that when comparing the FRT in the male practitioners and non-practitioners of physical activity, no significant difference was found. However, in the female practitioners and non-practitioners of physical activity, it was observed that the non-practitioners had a lower risk of falls, since they have moved more than those who practice physical activities. These data are also confirmed in a study by Ferreira, Ferreira and Escobar (2012), in which were assessed 33 female elderlies with mean age of 71 years, and were found significant correlation between FRT and the practice of physical exercise. The female non-practitioners had greater displacement $(33.95 \mathrm{~cm}+/-8.09)$ than the practitioners $(25.09 \mathrm{~cm}+/-7.43 \mathrm{~cm})$, demonstrating that women who do not practice physical activity have a lower risk of falling ${ }^{(18)}$.

The physical activity is important, since it is known that among its benefits are: reduction of functional losses, preservation of independence, improvement of posture and balance, reduction of anxiety and stress, as well as decrease in mood changes and increase in self-esteem ${ }^{(19)}$. Considering the above, it is believed that the results found in the present research, in which women practicing physical activity had a greater risk of falling, may be in parts associated with a small number of the sample and the type of physical activity of the studied group, most of whom identified water aerobics, dance and weight training, which do not work on the issue of flexibility and balance of elderly. It is suggested new studies that compare the types of physical activities. When compared the propensity to fall in the elderly female and male practitioners and non-practitioners of physical activities, it was observed in the present study that men performed the TUG in a shorter time and move more in the FRT, therefore women are at a higher risk of falls when compared to men. These data were verified by a study performed in 47 elderly people with mean age of 70 years. And It was observed that women had a higher risk of falling and being partially dependent on basic activities of daily living than men, since they are frequently carriers of more chronic conditions as depression, arthrosis, arthritis, among others, and also to be more exposed to extrinsic factors that cause sarcopenia, such as inadequate nutritional intake, which may explain the worse performance ${ }^{(20)}$. In this study, no difficulties were found for the execution of the TUG and FRT tests, presenting no intercurrence during their applications. The tests used were easy to apply and could be applied daily by the physiotherapist with the objective of evaluating the risk of falls, enabling the adoption of preventive measures in order to reduce its incidence in the elderly.

\section{CONCLUSION}

It was concluded that the female practitioners of physical activity have a greater risk of suffering an episode of fall compared to the non-practitioners, and in relation to the men practitioners and non-practitioners of physical activity there was no significant difference, showing that the elderly women have a higher risk to fall compared to the elderly men.

\section{AUTHORS CONTRIBUTIONS}

EAG: Guided the study design and reviewed all the phases of the research; CMB: Co-guided all the phases of the research; MPPA: Study design and writing, data collection; NRG: Study design and writing, data analysis and tabulation, statistical analysis; BVFT: Study design and discussion writing; KRL: Study design, methods and conclusion writing, final review of the article.

\section{CONFLICT OF INTERESTS}

The authors declare that there was no conflict of interests.

\section{AUTHORS DETAILS}

${ }^{2}$ Centro Universitário do Triângulo (UNITRI), Uberlândia (MG), Brasil.

${ }^{3}$ Universidade Federal do Triângulo Mineiro (UFTM), Uberaba (MG), Brasil.

\section{REFERENCES}

1. Nicolussi AC, Fhon JRS, Santos CAV, Kusumota L, Marques S, Rodrigues RAP. Qualidade de vida em idosos que sofreram quedas: revisão integrativa da literatura. Ciênc. saúde coletiva. 2012; 17(3): 723-730.

2. Meireles VC, Matsuda LM, Coimbra JAH, Mathias TAF. Características dos idosos em área de abrangência do Programa Saúde da Família na região noroeste do Paraná: contribuições para a gestão do cuidado em enfermagem. Saúde soc 2007.16(1): 69-80.

3. Melo NCV, Teixeira KMD, Barbosa TL, Montoya AJA, Silveira MB. Arranjo domiciliar de idosos no Brasil: análises a partir da Pesquisa Nacional por Amostra de Domicílios (2009). Revista Brasileira de Geriatria e Gerontologia. 2016; 19(1): 139-151.

4. Ilha S, Quintana JM, Santos SSC, Vidal DAS, Gautério DP, Backes DS. Quedas em idosos: reflexão para os enfermeiros e demais profissionais. Rev enferm UFPE. 2014;8(6): 1791-8. 
5. Maciel MG. Atividade física e funcionalidade do idoso. Motriz. 2010; 16(4): 1024-1032.

6. Figueiredo KMOB, Lima KC, Guerra RO. Instrumentos de avaliação do equilíbrio corporal em idosos. Rev. Bras. Cineantropom. Desempenho Hum. 2007; 9(4), 408-413.

7. Uzor S, Baillie L, Skelton DA, Rowe PJ. Falls prevention advice and visual feedback to those at risk of falling: study protocol for a pilot randomized controlled trial. Trials. 2013; 14(79): 1-8.

8. Silveira KRM, Matas SLA, Perracini MR. Avaliação do desempenho dos testes functional reach e lateral reach em amostra populacional brasileira. rev bras fisioter. 2006; 10(4): 381-386.

9. Siegel S, Jr Castellan NJ. O caso de k amostras independentes. In: Siegel S, Jr Castellan NJ. Estatística não-paramétrica, para as ciências do comportamento. São Paulo: McGraw-Hill do Brasil. 1975. p. 350.

10. Gasparotto LPR, Falsarella G R, Coimbra AMV. As quedas no cenário da velhice: conceitos básicos e atualidades da pesquisa em saúde. Rev. Bras. Geriatr. Gerontol. 2014; 17(1), 201-209.

11. Neto AFL, Guimarães RF. Atividade física e incidência de quedas em idosos. Revista Saúde e Desenvolvimento. 2012; 1(1): 28-43.

12. Bretan $\mathrm{O}$, Silva Júnior JE, Ribeiro OR, Corrente JE. Risco de queda em idosos da comunidade: avaliação com o teste Timed up and go. Brazilian Journal of otorhinolaryngology. 2013;79(1): 18-21.

13. Karuka AH, Silva JAMG, Navega MT. Análise da concordância entre instrumentos de avaliação do equilíbrio corporal em idosos. Rev Bras Fisioter. 2011; 15(6): 460-466.
14. Ribeiro F, Gomes S, Teixeira F, Brochado G, Oliveira J. Impacto da prática regular de exercício físico no equilíbrio, mobilidade funcional e risco de queda em idosos institucionalizados. Revista Port Cien Desp. 2009; 9(1): 36-42.

15. Lopes KT, Costa DF, Santos LF, Castro DP, Bastone AC. Prevalência do medo de cair em uma população de idosos da comunidade e sua correlação com mobilidade, equilíbrio dinâmico, risco e histórico de quedas. Rev Bras Fisioter. 2009; 13(3): 223-9.

16. Souza CC, Valmorbida LA, Oliveira JP, Borsatto AC, Lorenzini M, Knorst MR, Melo D, Creutzberg M, Resende TL. Mobilidade funcional em idosos institucionalizados e não institucionalizados. Rev Bras Geriatr Gerontol. 2013;16(2): 285-293.

17. Almeida ST, Soldera CLC, Carli GA, Gomes I, Lima Resende TL. Análise de fatores extrínsecos e intrínsecos que predispõem a quedas em idosos. Revista da Associação Médica Brasileira. 2012; 58(4): 427-433.

18. Ferreira CV, Ferreira CG, Escobar RV. Relação entre envelhecimento ativo, risco de queda e perfil funcional de idosos. Revista Equilíbrio Corporal e Saúde. 2012; 4(2): 27-41. 2012.

19. Ferreira TKA, Pires VATN. Atividade física na velhice: avaliação de um grupo de idosas sobre seus benefícios. Revista Enfermagem Integrada - Ipatinga: Unileste. 2015; 8(1): 130-1313.

20. Silva JMN, Barbosa MFS, Castro POCN, Noronha MM. Correlação entre o risco de queda e autonomia funcional em idosos institucionalizados. Rev. Bras. Geriatr. Gerontol. 2013; 16(2): 337-346. 